\title{
AGRICULTURE POTENTIAL ZONE IDENTIFICATION USING GIS TECHNIQUE IN THE HILLY TERRAIN BLOCK OF UTTARKASHI DISTRICT
}

\author{
Asha Thapliyal", Anju Panwar, M.P.S.Bisht \\ Uttarakhand Space Application Centre, (USAC) Dehradun-248007 \\ ashath08@gmail.com, ddndelhi@gmail.com
}

\section{Commission III, WG III/10}

Key Words: Watershed, Agriculture, Suitability, Weighted Sum, Quantile Classification

\begin{abstract}
Management could be improved through the use of current technologies including Remote Sensing and Geographic Information System (GIS). The present study was carried out to identify the potential agriculture sites in the Yamuna basin of Uttarkashi district of Uttarakhand .The characterization of natural resources of Yamuna basin of Uttarkashi district was undertaken using satellite imagery (Sentinel -2, LISS IV, LISS III, Aster DEM $(30 \mathrm{~m})$ and Survey of India Toposheet to generate several layers of maps such as Watershed Boundaries,Drainage, Soils, Land use and Land cover, Geology, Geomorphology, Lithology,Ground water, Slope and Aspect using Geographic Information System.The most influencing parameters of each layer were chosen based on literature and operational methodologies and they were extensively studied while taking in to consideration their role in determination of potential agriculture sites. Accordingly they were assigned definite weight in order to characterize the sites on basis of their potential Agriculture/Irrigation site values. Individual resources information was integrated in the GIS environment with the help of the weighted sum method to identify potential irrigation sites.Quantile classification was used to get more refined result. Census data sate agriculture department and irrigation department were used to verify the outcomes of result.
\end{abstract}

\section{INTRODUCTION}

Uttarkashi district was created on February 241960 .it sprawls in the extreme northwest corner of the state of Uttarakhand over an area of $8016 \mathrm{sq} \mathrm{km}$ in the rugged terrain of the mystic Himalayas. On its north lie Himachal Pradesh state and the territory of Tibet and the district of Chamoli in the East. The district acquires importance because of the two very significant glaciers Gangotri and Yamnotri The source of the two holy rivers Ganga and Yamuna respectively. Irrigating a large part of northern India.Agriculture in these areas suffers from many constraints. The availability of cultivable land itself is the greatest restricting factor on the development of agriculture .It can be seen from the fact that as much as $88 \%$ of the area is either covered by forest or its barren land or uncultivable. Shorter agriculture season low temperature, highaltitude, smallness of land holding perpetual problems of soil erosion due to steep gradients are other inhibiting facto affecting agriculture.Land and water resources management plans offer a definite approach for the management of natural resources. The basic concept for the proposed study and research is to find out quality of natural resources and ecological setup in a given area for potential agriculture practices. The proposed research was carried out to identify natural resources such as land use land cover, soil, geology, and geomorphology, and lithology, hydrogeomorphology condition of the subsurface aquifer, slope and aspect of the land and population behavior of the region. Agriculture is one of the most important occupations of the region so planning should be utmost priority of the state. The basic concept of the study is to find out quality of natural resources and ecological setup in a given area for potential irrigation practices the study was carried out to identify natural resources such as land cover, soil, geomorphology, and slope, aspect of the land and population behavior of the region. These resources were spatially correlated to each other to identify the potential agriculture hotspot in the Yamuna basin.

\section{STUDY AREA}

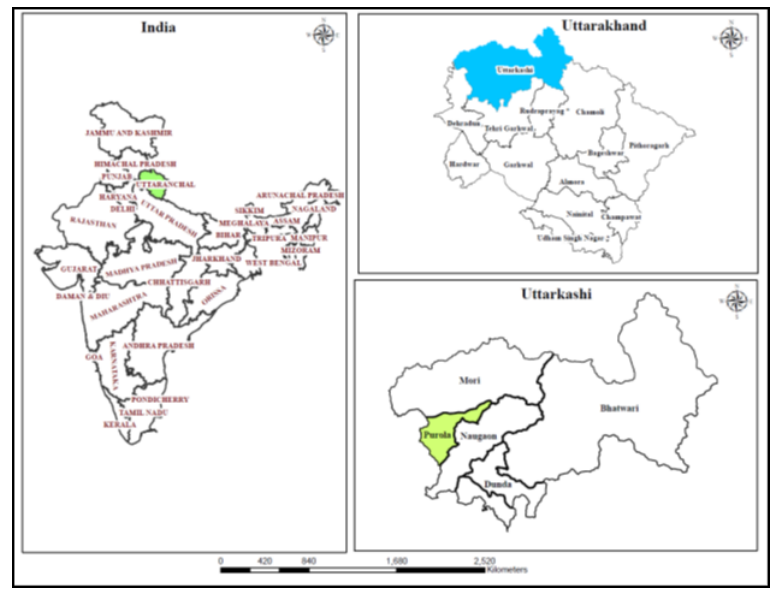

Fig. 1: Study Area

\section{METHODOLOGY}

The parameters selected for the study were texture, drainage and slope of the soil, land use land cover, geomorphology, slope and aspect. The satellite data used in the study was IRS P6 LISSS III (February 2017), Aster (30 m) data was also used for generating Digital Elevation Model for slope, aspect watershed related studies. The software's used in the study are Arc GIS 10.4.1 and ERDAS 14.

\footnotetext{
* Corresponding author
} 


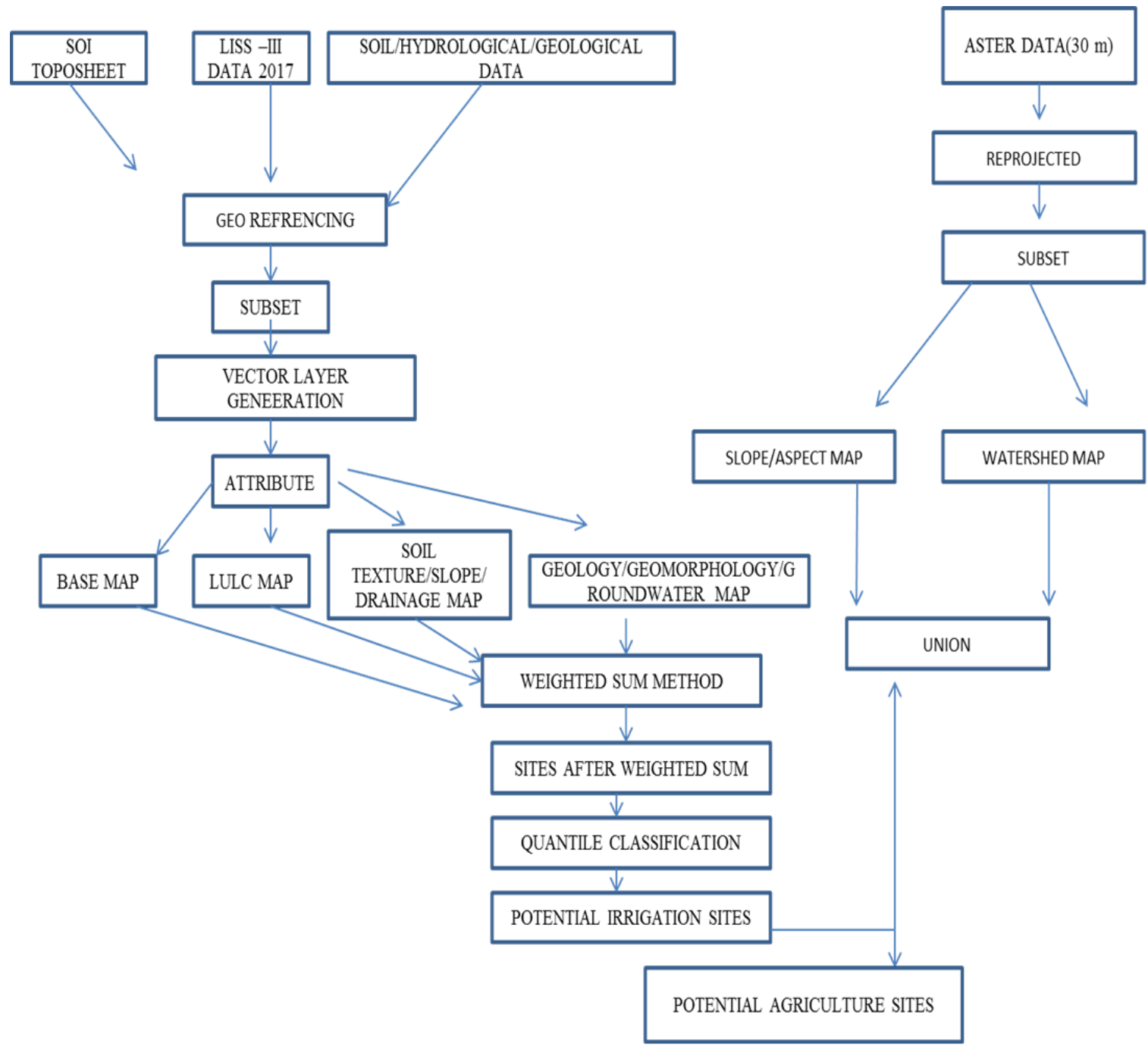

Fig.2: Flow Diagram of the methodology

\subsection{Thematic Resources Information Generation}

Various thematic resources maps were generated using remote sensing data including, ancillary information like literature, report and statistics data.

\subsubsection{Base map}

Base map was prepared using survey of India toposheets on 1:50,000 scales by incorporating various aspects like settlements, stream network and road network.

\subsubsection{Land use/land cover mapping}

The land use of an area is a result of interaction between various physical, economic and social factors. Land needs to be better matched for its uses to increase production. On the basis of visual interpretation of satellite imagery and available collateral data, major land use/ land cover classes were delineated.

\subsubsection{Soil mapping}

Soil is a major element in the natural environment linking climate and vegetation. National Bureau of Soil Survey \& Land Use Planning (NBBS \& LUP) map is prepared on 1:250,000 scale. This map was characterized based on three parameters: soil texture, drainage and soil slope.

\subsubsection{Slope mapping}

Slope of land is one of the important physiographic aspects which influence the Land capability. Slope map was prepared using DEM (SRTM 30 m).

\subsubsection{Aspect mapping}

The slope aspect is very important variable for plant growth and cultivation. The aspect causes variation in temperature and humidity on three kinds of slopes, namely those directly facing the sun, those partly facing the sun and those not facing the sun at all. Aspect categories are symbolized using hues and degree of slope classes are mapped with saturation so that the steeper slopes are brighter. Aspect map was generated using DEM (SRTM $30 \mathrm{~m}$ ).

\subsubsection{Geomorphology mapping}

Geomorphology is the study of landforms and the processes that shape them. Information on landforms is an important input for land and water management, soil mapping and identification of potential zones of surface and ground water occurrence. Survey 
of India Toposheets on 1:50,000 scale and satellite imagery were used to prepare Geomorphology map.

\subsection{Identification of Agriculture Sites}

Based on inter-correlations between and within the several thematic and resource information, the potential sites with their salient features were identified to extract surface / ground water for minor and medium irrigation projects. Each thematic information was classified to understand how these resources and their salient feature could help to explore potential site. Within a resource some salient features were considered as push factors and some feature were considered as pull factors and they were assigned weights accordingly.

3.2.1. Soil texture - The highest weight was given to loamy because of its high water holding capacity.

3.2.2. Soil slope - Gentle and very gentle slopes were assigned highest weights because they do not promote run-off and erosion. Accordingly steep slopes were given least weight.

3.2.3. Soil drainage - Well- drained soil was given more weight than the excessively drained.

3.2.4. Slope -0 to 10 degrees was given highest weight while the slopes of more than 50 degrees were assigned lowest weight.

3.2..5. Aspect - Flat, East and Southern aspects were given more weight than other aspects. Eastern aspect directly faces the Northeast monsoon winds. Southern aspect faces the Southwest monsoon winds.

3.2.6. Land use / Land Cover - Agriculture was given more weight than forest and grassland while wasteland and snow covered areas were given the least weight.

3.2.7. Geomorphology- River terrace and valley were given highest weight.

In Arc GIS, The Weighted Sum tool provides the ability to weight and combine multiple inputs to create an integrated analysis. It is similar to the Weighted Overlay tool in that multiple raster inputs, representing multiple factors, can be easily combined incorporating weights or relative importance. One major difference between the weighted overlay tool and the weighted Sum tool is the Weighted Sum tool allows for floating point values whereas the Weighted Overlay tool only accepts integer raster's as inputs. Generally, the values of continuous raster's are grouped into ranges, such as for slope, or Euclidean distance outputs, where each range is assigned a single value to represent a class such as low, medium or high importance. The Reclassify tool allows for such raster's to be reclassified.

\section{3. Quantile classification}

Quantile is one of the classes of values of a variant which divides the members of and batch or sample into equal - sized subgroups of adjacent values or a probability distribution into distributions of equal probability.

\subsection{Validation}

The settlement points were over layed on the final classified map and their proximity with the potential areas was observed .When compared with the February 2017 LISS III image, a very close resemblance was noticed.
Based on census 2011 data and the data from agriculture department, various village boundaries were digitized. The villages with irrigation facilities were over layed on the potential areas.

\section{RESULT}

About $16.79 \%$ of the total geographical area was classified as very good while another $19.97 \%$ comes under the good category for Agriculture purpose. This amount was arrived through all the possible thematic outcomes irrespective of

But all such area may not be possible for conversion to agriculture purposes. For example, areas which cannot be radically altered are forests land and social / cultural lands. The detailed study has covered the possibility of conjunctive use of surface and ground water in areas where actual irrigation and agriculture could be undertaken.

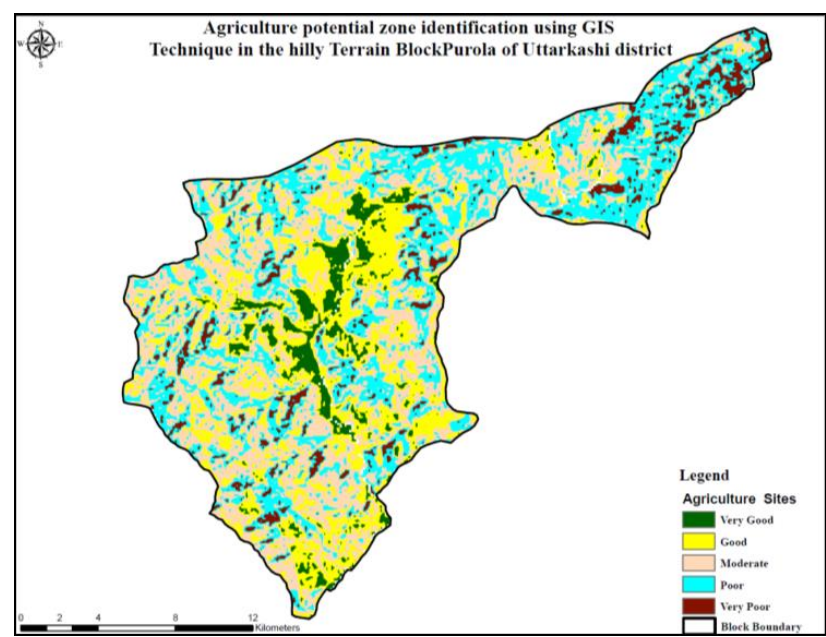

Fig.3: Agriculture Potential Map

\section{References}

Burrough, P.A., (1986), Principles of Geographic Information Systems for Land Resource Assessment. OUP, Oxford, 457pp.

Karanth, K. R., (1987), Ground water assessment, development and management, Tata McGraw-Hill publishing company Limited, New Delhi.

NRSC (2007), Manual for Ground Water Prospects Mapping using Remote Sensing techniques and Geographic Information System Rajiv.

Sabins, F.F. (1987). Remote Sensing Principles and Interpretation. (San Francisco, Calif.: W.H. Freeman), 449pp.

Semere Solomon. (2003). Remote Sensing and GIS: Applications for Groundwater Potential Assessment in Eritrea. Environmental and Natural Resources Information Systems. Royal Institute of Technology SE-100 44 Stockholm, 147pp.

Verstappen, H.Th. (1983). Applied Geomorphology, Geomorphologic Survey for Environmental Development, International Institute for Aerial Survey and Earth Science (I.T.C.) Enschede, the Netherlands, 434pp. 